\title{
Antithrombin activity and heparin response in neonates and infants undergoing congenital cardiac surgery: a retrospective cohort study
}

\section{Activité antithrombine et réponse à l'héparine chez les nouveau-nés et les nourrissons subissant une chirurgie cardiaque pour malformation congénitale: une étude rétrospective de cohorte}

\author{
Vannessa M. Chin, MBBS - Marie-Laure Laskine Holland, MD • \\ Marlee M. Parker, CPC, CCP • Helen M. Holtby, MBBS • \\ James D. O'Leary, MBBCh iD \\ Received: 7 April 2015/Revised: 3 August 2015/Accepted: 17 September 2015/Published online: 2 October 2015 \\ (C) Canadian Anesthesiologists' Society 2015
}

\begin{abstract}
Purpose The immature coagulation system during infancy has age-related physiological differences in proteins that contribute to significant variation in heparin responsiveness through alterations in heparin-enhanced thrombin inhibition. The primary aim of this study was to evaluate the relationship between preoperative antithrombin (AT) activity and heparin responsiveness in neonates and infants undergoing congenital cardiac surgery.

Methods In this retrospective cohort study, neonates (aged 0-28 days) and infants (aged 29-365 days) undergoing congenital cardiac surgery in the 12-month period from October 2013 to 2014 were studied. The two age groups were compared for the primary endpoint of
\end{abstract}

This manuscript was screened for plagiarism using Cross Check.

Author contributions Vannessa M. Chin, Marie-Laure Laskine Holland, Marlee M. Parker, Helen M. Holtby, and James D. O'Leary helped design the study and write the manuscript. Vannessa M. Chin and James D. O'Leary helped conduct the study, analyze the data, and review the analysis of the data. James D. O'Leary is the author responsible for archiving the study files.

V. M. Chin, MBBS · M.-L. L. Holland, MD .

M. M. Parker, CPC, CCP - H. M. Holtby, MBBS .

J. D. O'Leary, MBBCh

The Hospital for Sick Children, Toronto, ON, Canada

J. D. O’Leary, MBBCh $(\bowtie)$

Division of Cardiac Anesthesia, The Hospital for Sick Children,

Rm 2212J, 555 University Avenue, Toronto, ON M5G 1X8,

Canada

e-mail: james.oleary@sickkids.ca heparin response measured by the heparin sensitivity index (HSI), with heparin loading doses and heparin resistance being secondary endpoints. Multivariable linear regression analyses were used to explore the relationship between AT activity and heparin response measured by HSI.

Results There were 122 infants and 19 neonates included in the study. After adjusting for low-molecular-weight heparin, unfractionated heparin, and platelet count, there was a significant relationship between AT activity and HSI $(r=0.44 ; P=0.009)$. The median [interquartile range] HSI did not differ between neonates and infants 10.76

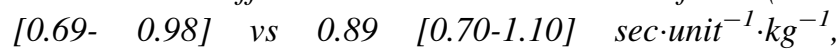
respectively; median difference, 0.08; 95\% confidence interval [CI], -0.01 to $0.17 ; P=0.182$ ), despite the mean (standard deviation) AT activity differing between age groups $[60$ (16)\% vs 84 (18)\%, respectively; mean difference, 24; $95 \% \mathrm{CI}, 15$ to 32; $P<0.001]$.

Conclusions There was a moderate relationship between AT activity and heparin response measured by HSI. Comparing neonates and infants, there was similar heparin responsiveness measured by HSI despite differing AT activity levels. These findings should help guide the perioperative administration of exogenous AT to neonates and infants and suggest that, outside the neonatal period, preoperative AT activity may be used to identify children at risk of decreased heparin responsiveness.

Résumé

Objectif Au cours de la petite enfance, les protéines $d u$ système de coagulation immature présentent des 
différences physiologiques liées à l'âge qui contribuent à la variabilité significative de la réponse à l'héparine via des altérations de l'inhibition de la thrombine activée par l'héparine. L'objectif principal de cette étude était d'évaluer les rapports entre l'activité antithrombine (AT) préopératoire et la réponse à l'héparine chez des nouveau-nés et des nourrissons subissant une chirurgie cardiaque pour malformation congénitale.

Méthodes Dans cette étude de cohorte rétrospective, nous avons étudié des nouveau-nés (âgés de 0 à 28 jours) et des nourrissons (âgés de 29 à 365 jours) subissant une chirurgie cardiaque pour malformation congénitale pendant une période de 12 mois, d'octobre 2013 à octobre 2014. Les deux groupes d'âge ont été comparés par rapport au principal critère d'évaluation (réponse à l'héparine mesurée par l'indice de sensibilité à l'héparine [HSI]) et aux critères d'évaluation secondaires (les doses de charge d'héparine et la résistance à l'héparine). Des analyses de régression linéaire multifactorielle ont servi à explorer les rapports entre l'activité AT et la réponse à l'héparine mesurée par le HSI.

Résultats L'étude a inclus 122 nourrissons et 19 nouveau-nés. Après ajustement pour l'héparine de bas poids moléculaire, l'héparine non fractionnée et la numération plaquettaire, une relation significative a été constatée entre l'activité AT et le HSI ( $r=0,44$; $P=0,009$ ). Le HSI médian [intervalle interquartile] n'a pas été différent entre les nouveau-nés et les nourrissons (respectivement, 0,76 [0,69 - 0,98] contre 0,89 [0,70 1,10] sec.unité ${ }^{-1} \cdot \mathrm{kg}^{-1}$; différence des médianes: 0,08; intervalle de confiance [IC] à $95 \%$ : -0,01 à -0,17; $p=$ 0,182), alors que l'activité AT moyenne (écart-type) était différente entre les groupes d'âge (respectivement 60 [16] \% contre 84 [18]\%; différence moyenne: 24; IC à $95 \%, 15$ à 32; $P=0,001$ ).

Conclusions Il y a eu un lien modéré entre l'activité AT et la réponse à l'héparine mesurée par le HSI. En comparant les nouveau-nés et les nourrissons, la réactivité à l'héparine mesurée par HSI a été similaire en dépit de niveaux d'activité AT différents. Ces constatations devraient contribuer à guider l'administration périopératoire d'AT exogène à des nouveau-nés et à des nourrissons; elles suggèrent également qu'en dehors de la période néonatale, l'activité AT peut servir à identifier les enfants à risque de réponse diminuée à l'héparine.

The coagulation system in early childhood is immature and shows age-related physiological differences in the binding and quantity of proteins. ${ }^{1,2}$ Antithrombin (AT), a 432 aminoacid protein, is a serine protease inhibitor and the principal inhibitor of thrombin and factor $\mathrm{Xa}^{3}$ The primary mechanism of heparin anticoagulation is the enhancement of thrombin inhibition by the binding of heparin to AT at a specific pentasaccharide sequence on the heparin molecule. ${ }^{4}$ This multistep allosteric interaction increases AT activity 2,000-4,000-fold, but there is significant interindividual variation in heparin responsiveness. ${ }^{5}$ The heparin response in vivo is multifactorial, but it is hypothesized that deficiency in AT is the primary pathway responsible for decreased heparin responsiveness. ${ }^{6}$

Decreased AT activity is more common in neonates and infants than in adults, ${ }^{7}$ and normal activity levels are not reached until at least six months of age. ${ }^{8}$ Acquired AT deficiency can also occur with a variety of pathophysiological conditions, including sepsis, liver dysfunction, and disseminated intravascular coagulation. ${ }^{6}$ In addition, children with congenital cardiac defects, who are at higher risk for thrombosis due to an immature coagulation system or complex surgical palliations, are frequently prescribed platelet inhibitors, low-molecularweight heparin, or unfractionated heparin (UFH) for the prevention or treatment of thromboembolic events, all of which can be associated with decreased AT activity. ${ }^{9}$

In vitro, a positive relationship between AT activity and heparin responsiveness has been shown, especially with low AT activity. ${ }^{10}$ Nevertheless, no significant correlation between AT activity and heparin responsiveness has been shown for children undergoing congenital cardiac surgery. ${ }^{11}$ These findings are influenced, however, by the precision and reliability of both the hemostasis management system (HMS) used to estimate activated clotting time (ACT) and laboratory techniques used to determine AT activity. ${ }^{12,13}$

Serious complications of thrombosis and bleeding occur frequently following congenital cardiac surgery. ${ }^{14}$ Subtherapeutic heparin anticoagulation can directly influence these outcomes, ${ }^{6}$ and early identification of children at risk of AT-dependent heparin resistance would optimize intraoperative anticoagulation strategies by guiding the use of exogenous AT prior to heparin loading. ${ }^{15}$

The aim of this study was to evaluate the relationship between preoperative AT activity and heparin responsiveness in neonates and infants undergoing congenital cardiac surgery. Our primary hypothesis was that heparin response is directly related to AT activity in young children undergoing congenital cardiac surgery. Our secondary hypothesis was that neonates and infants differ in heparin responsiveness due to age-related physiological differences in AT activity.

\section{Methods}

With approval (REB1000047512 - November, 2014) from the local Research Ethics Board, neonates and infants who 
underwent congenital cardiac surgery with heparin anticoagulation at The Hospital for Sick Children, Toronto were included in this retrospective cohort study.

\section{Eligibility}

Children aged less than one year were eligible for inclusion. Exclusion criteria were the absence of preoperative investigation of AT activity, an incomplete intraoperative hemostasis management record (ACT, heparin dose, or heparin concentration), the use of extracorporeal membrane oxygenation prior to surgery, or an ACT exceeding the upper limit of measurement (>999 sec) after heparin loading.

Data collection

All children who received heparin anticoagulation to facilitate cardiopulmonary bypass (CPB) during congenital cardiac surgery at The Hospital for Sick Children, Toronto prior to October 31, 2014 were consecutively assessed for study eligibility backwards from that date until the sample size requirement was met. The same investigator (V.C.) reviewed the intraoperative perfusion and electronic health records of all patients screened for eligibility and performed all data extraction. Demographic data collected included age, sex, weight, height, and preoperative oxyhemoglobin saturation. Children were categorized by age group, i.e., neonates (aged 0-28 days) and infants (aged 29-365 days). Surgical characteristics collected included type of congenital cardiac surgery and details of preoperative platelet inhibition or anticoagulation. Preoperative laboratory investigations included were AT activity, activated partial thromboplastin time (APTT), international normalized ratio (INR), hematocrit, hemoglobin, and platelet count.

Laboratory investigations

All laboratory investigations included in the study were routinely performed for clinical purposes and conducted by a central laboratory according to institutional protocols. The BIOPHEN Antithrombin 5 assay (HYPHEN BioMed, France) was used for the quantitative determination of the heparin cofactor activity of AT in human citrated plasma using the anti-Xa method. For this assay, the relationship between released pNA (4-nitroaniline) measured as absorbance at $405 \mathrm{~nm}$ and the level of AT is linear in the $80-120 \%$ range of normal plasma, and AT activity $<70 \%$ indicates the presence of a deficiency.

Intraoperative anticoagulation

Intraoperative ACT and a heparin loading dose were calculated by a point-of-care HMS (HMS Plus; Medtronic Perfusion Services, Minneapolis, MN, USA). Heparin dose response (HDR) and High Range ACT cartridges (Medtronic Perfusion Services, Minneapolis, MN, USA) were used for the relevant HMS measurements. The HMS was calibrated to manufacturer standards using HEPtrac ${ }^{\mathrm{TM}}$ electronic and lyophilized quality controls. Heparin sodium (DIN 02303086) (Sandoz Canada Incorporated, Boucherville, QC, Canada) 1,000 units $\cdot \mathrm{mL}^{-1}$ was used for all patients.

The heparin loading dose was estimated from the HDR for all children, and an ACT $>480 \mathrm{sec}$ was targeted before CPB was initiated. Heparin resistance was defined as a

FIGURE Flow diagram

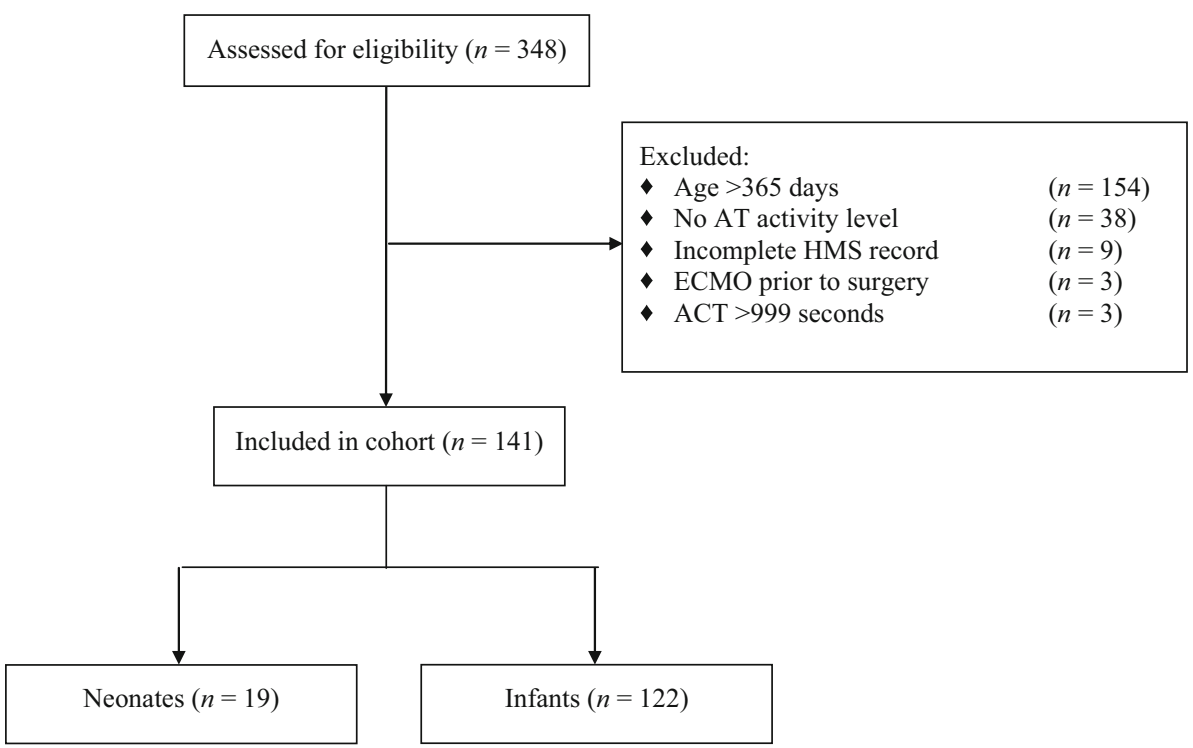


failure to reach an ACT $>480 \mathrm{sec}$ after an initial heparin loading dose of $>400$ units $\cdot \mathrm{kg}^{-1},{ }^{6}$ and the decision to administer either exogenous AT concentrate or fresh frozen plasma (FFP) was at the discretion of the attending anesthesiologist. All children received a bolus of tranexamic acid $\left(30 \mathrm{mg} \cdot \mathrm{kg}^{-1}\right.$ ) prior to measuring ACT after heparin loading.

\section{Outcomes}

The primary outcome was heparin response measured by the heparin sensitivity index (HSI), which is defined as the difference between ACT after heparin administration and baseline ACT divided by the heparin loading dose per kilogram. ${ }^{6}$ The secondary outcomes were heparin response measured by heparin resistance and heparin loading dose administered.

\section{Statistical analysis}

To perform multiple linear regression analysis using up to nine (an a priori estimate) predictor variables with an anticipated medium effect size of $0.15\left(f^{2}\right)$, we predicted that a minimum sample size of 141 study participants was needed at an alpha error of 0.05 and power of 0.9.

Data were recorded in Excel (Microsoft). All analyses were performed using Stata ${ }^{\circledR} 13$ (StataCorp LP, TX, USA). The distribution of data was estimated using skewness and kurtosis normality tests and Q-Q plots. Descriptive statistics for participants, according to age group, were determined as appropriate for the data distribution. Data are presented as mean and standard deviation (SD) when normally distributed, or median and interquartile range [IQR] when not normally distributed. Between-group analyses were performed using Wilcoxon rank-sum test for continuous data not normally distributed, Student's $t$ test for normally distributed continuous data, and Fisher's exact test for categorical data. Mean differences and Hodges-Lehmann median differences with $95 \%$ confidence intervals (CI) were used to assess differences between groups. Univariate regression was used to identify potential confounding factors and/or effect modification from demographic, clinical, and laboratory characteristics of the study population for both dependent (HSI) and independent (AT activity) variables. Univariate outcomes with statistical significance of $P<0.25$ were included in the base multivariable regression model. A backward-stepwise multivariable linear regression analysis was used to model the relationship between heparin response measured by HSI (dependent variable) and AT activity (independent variable). A Bonferroni correction was used to correct for three multiple comparisons, and statistical significance was defined as $P<0.017$ (two-sided).

\section{Results}

Three hundred forty-eight children undergoing congenital cardiac surgery at The Hospital for Sick Children, Toronto were assessed for study eligibility, and 141 children were included in the final analysis (Figure). Characteristics of children included in the cohort are summarized in Table 1. All children were $\geq 36$ weeks gestational age on the day of surgery.

Using formal testing of data distribution, AT activity and heparin concentration were normally distributed, but all other laboratory and intraoperative coagulation data were non-normally distributed. Subsequent inspection of Q-Q plots indicated that hemoglobin, hematocrit, platelet count, ACT, and heparin dose per kg approximated to a normal distribution with short tails at both ends of the data distribution. Results of preoperative laboratory investigations are summarized in Table 2. Intraoperative coagulation, heparin management, and heparin responsiveness data are summarized in Table 3.

Antithrombin activity was moderately associated with age $(\mathrm{r}=0.42 ; P<0.001)$, weight $(\mathrm{r}=0.54 ; P<0.001)$, height $(\mathrm{r}=0.47 ; P<0.001)$, and preoperative UFH exposure $(\mathrm{r}=-0.44 ; P<0.001)$, and weakly associated with platelet count $(\mathrm{r}=0.33 ; P<0.001)$, INR $(\mathrm{r}=-0.35$; $P<0.001)$ and preoperative use of low-molecular-weight heparin $(\mathrm{r}=0.22 ; P=0.010)$. There was no evidence of any relationship between AT activity and other patient characteristics or preoperative laboratory investigations.

There was a weak association between HSI and preoperative use of UFH $(\mathrm{r}=-0.33 ; P<0.001)$, weight $(\mathrm{r}=0.32 ; P<0.001)$, and APTT $(\mathrm{r}=-0.26 ; P=0.002)$. There was no significant relationship between HSI and other patient characteristics or preoperative laboratory investigations.

On unadjusted analysis, there was initially a weak association between AT activity and HSI $(\mathrm{r}=0.27 ; P=$ 0.001 ), and after adjusting for confounding factors, this association remained statistically significant $(\mathrm{r}=0.44 ; P=$ 0.009) (Table 4).

The median [IQR] heparin loading dose, determined by point-of-care HMS to reach a target ACT $>480 \mathrm{sec}$, differed between neonates and infants (469 [452-480] units $\cdot \mathrm{kg}^{-1}$ vs 454 [414-466] units $\mathrm{kg}^{-1}$, respectively; median difference, $-16 ; 95 \% \mathrm{CI},-31$ to $-6 ; P=$ 0.007). Heparin resistance occurred in $31.2 \%(n=44)$ of children. Of these children, $43.2 \%(n=19)$ were deficient in AT and $18.2 \%(n=8)$ were neonates. Overall, $24.1 \%(n$ $=34$ ) of children received additional heparin after the HMS recommended heparin loading dose, and $1.4 \%(n=2)$ received FFP to reach a target ACT $>480 \mathrm{sec}$. No children received exogenous AT during the intraoperative period. 
Table 1 Characteristics of neonates and infants undergoing congenital cardiac surgery

\begin{tabular}{llll}
\hline Characteristic & $\begin{array}{l}\text { All children } \\
(n=141, \text { unless specified })\end{array}$ & $\begin{array}{l}\text { Neonates } \\
(n=19, \text { unless specified })\end{array}$ & $\begin{array}{l}\text { Infants } \\
(n=122, \text { unless specified })\end{array}$ \\
\hline Age in days, median [IQR] & $156[87-203]$ & $7[5-11]$ & $168[129-212]$ \\
Female, $n(\%)$ & $74(52.5)$ & $10(52.6)$ & $64(52.5)$ \\
Weight (kg), (MSD) & $5.3(1.6)$ & $3.0(0.6)$ & $5.7(1.3)$ \\
Height (cm), median [IQR] & $61[56-65]$ & $50[47-52]$ & $62[59-66]$ \\
Room air oxyhemoglobin saturation $\leq 85 \%, n(\%)$ & $39 / 136(28.7)$ & $7 / 17(41.2)$ & $32 / 119(26.9)$ \\
Preoperative medications: $n(\%)$ & & & $<0.001$ \\
Acetylsalicylic acid & $6(4.3)$ & $0(0.0)$ & $6(4.9)$ \\
Clopidogrel & $1(0.7)$ & $0(0.0)$ & $1(0.8)$ \\
LMWH & $20(14.2)$ & $0(0.0)$ & $20(16.4)$ \\
Unfractionated heparin & $8(5.7)$ & $1(5.3)$ & $7(5.7)$ \\
Type of congenital cardiac surgery: $n(\%)$ & & & 1.000 \\
Extracorporeal assist device & $1(0.7)$ & $0(0.0)$ & 1.000 \\
Repair & $113(93.4)$ & $17(89.5)$ & 0.075 \\
Palliation & $26(18.4)$ & $2(10.5)$ & 1.000 \\
Transplant & $2(1.4)$ & $0(0.0)$ & $95(77.9)$ \\
Valve replacement & $1(0.7)$ & $0(0.0)$ & $22(18.0)$ \\
Other (embolectomy) & $1(0.7)$ & $1(5.3)$ & $2(1.6)$ \\
\hline
\end{tabular}

$\mathrm{IQR}$ = interquartile range; LMWH = low-molecular-weight heparin; MSD = mean standard deviation

There was no significant difference in the median [IQR] heparin response for neonates and infants measured by HSI (0.76 [0.69-0.98] $\quad$ sec $\cdot \mathrm{unit}^{-1} \cdot \mathrm{kg}^{-1}$ vs $0.89 \quad[0.70-1.10]$ sec. unit $^{-1} \cdot \mathrm{kg}^{-1}$, respectively; median difference, 0.08 ; 95\% CI, -0.01 to $0.17 ; P=0.182$ ) despite mean (SD) AT activity differing significantly between age groups [60 (16)\% vs 84 (18)\%, respectively; mean difference, $24 ; 95 \%$ CI, 15 to 32; $P<0.001]$. When comparing groups with different levels of AT activity, children with AT deficiency $(<70 \%)(n=34)$ had decreased median [IQR] heparin responsiveness measured by HSI compared with children with normal AT activity levels $(n=107)(0.71$ [0.60-0.85] sec $\cdot$ unit $^{-1} \cdot \mathrm{kg}^{-1}$ vs $\quad 0.91 \quad[0.77-1.10] \quad$ sec $\cdot \mathrm{unit}^{-1} \cdot \mathrm{kg}^{-1}$, respectively; median difference, $0.20 ; 95 \% \mathrm{CI}, 0.11$ to $0.29 ; P=0.001)$.

\section{Discussion}

Results of this study showed a moderate relationship between AT activity and heparin response measured by HSI for neonates and infants undergoing congenital cardiac surgery after adjusting for confounding factors; children deficient in AT had decreased heparin responsiveness measured by HSI compared with children with normal AT activity. Neonates required higher heparin loading doses than infants, but there was no difference in heparin responsiveness measured by HSI between age categories despite more neonates being deficient in AT activity.
Heparin resistance occurred commonly, i.e., in more than $30 \%$ of children.

This finding of decreased heparin responsiveness in children with AT deficiency contrasts with a previous study by Dietrich et al. who reported that heparin response measured by HSI differed among adults undergoing cardiac surgery according to AT deficiency but not among neonates and infants. ${ }^{11}$ In a post hoc analysis of our data using the same threshold as Dietrich et al. to define AT deficiency (i.e., $<80 \%$ ), the difference in HSI between deficient and normal AT activity groups remained significant. We hypothesize that this novel positive finding may be a function of the lower proportion of neonates in our cohort compared with Dietrich et al. (13\% vs $30 \%$, respectively) and is consistent with the agedependent differences in heparin response observed in both of these studies for patients with normal and deficient AT activity. ${ }^{11}$ In addition, differences in these findings may have been influenced by the methods used to determine AT activity (thrombin $v s$ anti-Xa chromogenic assays) and the types of HMS used (Hemochron 800 [International Technidyne Corp., Edison, NJ, USA] vs HMS Plus). ${ }^{12,13}$

Similar to other clinical studies investigating the relationship between AT and heparin responsiveness, we were unable to reproduce the strong positive association that exists in vivo between AT and heparin responsiveness. ${ }^{10,16}$ This suggests that decreased heparin response in vivo is multifactorial, and the lack of a strong association between AT activity and heparin responsiveness may be a 
Table 2 Preoperative laboratory results for neonates and infants undergoing congenital cardiac surgery

\begin{tabular}{|c|c|c|c|c|}
\hline Investigation, median [IQR] unless stated & $\begin{array}{l}\text { All children } \\
(n=141)\end{array}$ & $\begin{array}{l}\text { Neonates } \\
(n=19)\end{array}$ & $\begin{array}{l}\text { Infants } \\
(n=122)\end{array}$ & $P$ value \\
\hline$\%$ AT activity, mean (SD) & $81(19)$ & $60(16)$ & $84(18)$ & $<0.001$ \\
\hline AT activity $<70 \%, n(\%)$ & $34(24.1)$ & $13(68.4)$ & $21(17.2)$ & $<0.001$ \\
\hline Hemoglobin $\left(g \cdot \mathrm{L}^{-1}\right)$ & 132 [121-147] & 145 [124-159] & $132[120-146]$ & 0.062 \\
\hline Hematocrit $(\%)$ & $40[36-46]$ & $44[36-50]$ & $40[36-45]$ & 0.171 \\
\hline Platelet count $\left(\times 10^{9} \cdot \mathrm{L}^{-1}\right)$ & 358 [287-426] & $278[143-426]$ & $363[297-428]$ & 0.059 \\
\hline APTT (sec) & $34[32-38]$ & 38 [34-43] & $34[32-38]$ & 0.013 \\
\hline INR & $1.1[1.0-1.2]$ & $1.2[1.1-1.4]$ & $1.1[1.0-1.2]$ & $<0.001$ \\
\hline
\end{tabular}

$\mathrm{AT}=$ antithrombin; $\mathrm{APTT}=$ activated partial thromboplastin time; INR = international normalized ratio; IQR = interquartile range; $\mathrm{SD}=$ standard deviation

Table 3 Intraoperative coagulation and heparin management for neonates and infants undergoing congenital cardiac surgery

\begin{tabular}{lllll}
\hline Characteristic, median [IQR] & $\begin{array}{l}\text { All children } \\
(n=141)\end{array}$ & $\begin{array}{l}\text { Neonates } \\
(n=19)\end{array}$ & $\begin{array}{l}\text { Infants } \\
(n=122)\end{array}$ & $\begin{array}{l}\text { Median difference between } \\
\text { age groups, (95\% CI) }\end{array}$ \\
\hline Baseline ACT (sec) & $137[128-147]$ & $128[123-154]$ & $138[129-147]$ & $2(-10$ to 13) \\
ACT after heparin bolus (sec) & $509[457-584]$ & $490[461-544]$ & $514[456-595]$ & $14(-20$ to 48$)$ \\
Heparin loading dose $\left(\mathrm{IU} \cdot \mathrm{kg}^{-1}\right)$ & $456[421-456]$ & $469[452-480]$ & $454[414-466]$ & $-16(-31$ to -6$)$ \\
Heparin sensitivity index $\left(\mathrm{sec} \cdot \mathrm{unit}^{-1} \cdot \mathrm{kg}^{-1}\right)$ & $0.86[0.70-1.06]$ & $0.76[0.69-0.98]$ & $0.89[0.70-1.10]$ & $0.08(-0.01$ to 0.17$)$ \\
\hline
\end{tabular}

$\mathrm{ACT}=$ activated clotting time; $\mathrm{CI}=$ confidence interval; $\mathrm{IQR}=$ interquartile range

consequence of other endogenous and exogenous mechanisms. ${ }^{6}$ Antithrombin-independent anticoagulation also occurs by heparin cofactor II-mediated thrombin inactivation and, at higher heparin concentrations, by inhibition of fibrin-bound thrombin. ${ }^{17,18}$ Alternatively, heparin activity can be reduced by extravascular sequestration $^{19}$ and by an increased binding to plasma proteins such as histidine-rich glycoproteins, ${ }^{20}$ platelet factor 4 released from activated platelets, ${ }^{21}$ and neutrophilderived lactoferrin. ${ }^{22}$ In addition, other factors such as hypothermia, hemodilution, and increased binding to acutephase plasma proteins will have variable effects on heparin pharmacodynamics and pharmacokinetics in children undergoing cardiac surgery.

Compared with adults, heparin in younger children has a larger volume of distribution, increased clearance, and a shorter dose-dependent half-life. ${ }^{23,24}$ Similarly, the pharmacodynamics of heparin are age dependent, with decreased antithrombotic effects measured by anti-Xa and anti-IIa activity in younger children. ${ }^{23}$ This is likely due to age-related differences in protein structures affecting the binding of heparin to plasma proteins. ${ }^{1}$ The differences in heparin loading doses administered to neonates and infants reported here are consistent with the expected age-dependent effects of heparin, with neonates requiring larger heparin loading doses than infants. However, the heparin loading doses used in this study are larger than doses used in some other clinical studies investigating heparin responsiveness in children. This may be a consequence of several factors, including calculation of heparin loading doses using HDR rather than empirical methods and variability in heparin potency, ${ }^{25}$ both of which prevent us from reliably comparing heparin loading doses and measures of heparin response in this study with older clinical studies.

In this study, using a definition of failure to reach an ACT $>480 \mathrm{sec}$ after an initial heparin loading dose of $>400$ units $\cdot \mathrm{kg}^{-16}$ heparin resistance was found in over $30 \%$ of children. This rate of heparin resistance was high compared with some other studies (4-26\%). ${ }^{6}$ Importantly, more neonates were deficient in AT activity than infants (68\% vs $17 \%$, respectively), consistent with the normal physiological ranges in these age groups. Nevertheless, most children (57\%) in this study who required additional heparin loading to achieve a target ACT $>480 \mathrm{sec}$ had normal AT activity levels, and only two children (1.4\%) required exogenous AT (FFP) administration. This relative increase in heparin resistance may be multifactorial in etiology but is significantly influenced by the definition chosen for heparin resistance. Importantly, there is a distinct risk of a misclassification bias when defining heparin resistance in children due to the range of definitions currently in use and the practice of extrapolating adult definitions of heparin resistance to pediatric populations. Age-specific definitions of heparin 
Table 4 Multivariable linear regression model of AT activity and heparin sensitivity index

\begin{tabular}{|c|c|c|c|c|}
\hline $\begin{array}{l}\text { Variable } \\
\text { Model: HSI (four variables) }\end{array}$ & Coefficient & $95 \% \mathrm{CI}$ & $P$ value & VIF \\
\hline Intercept & 0.819 & 0.563 to 1.075 & - & - \\
\hline AT activity & 0.399 & 0.100 to 0.698 & 0.009 & 1.41 \\
\hline LMWH & -0.182 & -0.326 to -0.039 & 0.013 & 1.05 \\
\hline UFH & -0.340 & -0.553 to -0.128 & 0.002 & 1.25 \\
\hline Platelet count & -0.0004 & -0.001 to -0.000 & 0.034 & 1.12 \\
\hline
\end{tabular}

$\mathrm{AT}=$ antithrombin; $\mathrm{CI}=$ confidence interval; HIS = heparin sensitivity index; LMWH = low-molecular-weight heparin; UFH $=$ unfractionated heparin; VIF = variance inflation factor

resistance may be more appropriate for use in childhood due to age-dependent differences in heparin pharmaco dynamics and pharmacokinetics in children. ${ }^{23,26}$

The central limitation of this study was the use of HMSderived data alone (i.e., without antithrombin measurement) to measure heparin responsiveness. The limitations of ACT for measuring intraoperative heparin response during cardiac surgery in young children have been well described, ${ }^{27,28}$ but this was unavoidable due to the retrospective nature of the study design. Using a retrospective study design has other disadvantages, particularly increased risks of observer and selection biases, but these were mitigated in this study by using objective laboratory outcomes and including all children who presented for surgery during the study period respectively. Finally, the study was powered to detect a medium effect size using multiple linear regression, not traditional hypothesis testing, and as a result of the low number $(n=19)$ of neonates in the cohort there is a distinct risk of a type II error when estimating differences in outcomes between age groups.

In conclusion, there was a moderate relationship between AT activity and heparin response measured by HSI. Comparing neonates and infants, there was similar heparin responsiveness when measured by HSI despite differing AT activity levels. These findings should help guide the perioperative administration of exogenous AT to neonates and infants and suggest that, outside of the neonatal period, preoperative AT activity may be used to identify children at risk of decreased heparin responsiveness.

Funding No funding.

Competing interests None declared.

\section{References}

1. Ignjatovic V, Straka E, Summerhayes R, Monagle P. Age-specific differences in binding of heparin to plasma proteins. J Thromb Haemost 2010; 8: 1290-4.
2. Attard C, van der Straaten T, Karlaftis V, Monagle P, Ignjatovic V. Developmental hemostasis: age-specific differences in the levels of hemostatic proteins. J Thromb Haemost 2013; 11: 1850-4.

3. Huntington JA. Thrombin inhibition by the serpins. J Thromb Haemost 2013; 11(Suppl 1): 254-64.

4. Hirsh J, Raschke R, Warkentin TE, Dalen JE, Deykin D, Poller L. Heparin: mechanism of action, pharmacokinetics, dosing considerations, monitoring, efficacy, and safety. Chest 1995; 108: 258S-75S.

5. Bloemen S, Hemker HC, Al Dieri R. Large inter-individual variation of the pharmacodynamic effect of anticoagulant drugs on thrombin generation. Haematologica 2013; 98: 549-54.

6. Finley A, Greenberg C. Review article: heparin sensitivity and resistance: management during cardiopulmonary bypass. Anesth Analg 2013; 116: 1210-22.

7. Patnaik MM, Moll S. Inherited antithrombin deficiency: a review. Haemophilia 2008; 14: 1229-39.

8. Andrew M, Paes B, Milner R, et al. Development of the human coagulation system in the full-term infant. Blood 1987; 70: 165-72.

9. McCrindle BW, Li JS, Manlhiot C, et al. Challenges and priorities for research: a report from the National Heart, Lung, and Blood Institute (NHLBI)/National Institutes of Health (NIH) Working Group on thrombosis in pediatric cardiology and congenital heart disease. Circulation 2014; 130: 1192-203.

10. Despotis GJ, Levine V, Joist JH, Joiner-Maier D, Spitznagel E. Antithrombin III during cardiac surgery: effect on response of activated clotting time to heparin and relationship to markers of hemostatic activation. Anesth Analg 1997; 85: 498-506.

11. Dietrich W, Braun S, Spannagl M, Richter JA. Low preoperative antithrombin activity causes reduced response to heparin in adult but not in infant cardiac-surgical patients. Anesth Analg 2001; 92: 66-71.

12. Demers $C$, Henderson $P$, Blajchman $M A$, et al. An antithrombin III assay based on factor Xa inhibition provides a more reliable test to identify congenital antithrombin III deficiency than an assay based on thrombin inhibition. Thromb Haemost 1993; 69: 231-5.

13. Ojito JW, Hannan RL, Burgos MM, et al. Comparison of pointof-care activated clotting time systems utilized in a single pediatric institution. J Extra Corpor Technol 2012; 44: 15-20.

14. Manlhiot C, Menjak IB, Brandao LR, et al. Risk, clinical features, and outcomes of thrombosis associated with pediatric cardiac surgery. Circulation 2011; 124: 1511-9.

15. Ranucci M, Isgro G, Cazzaniga A, Soro G, Menicanti L, Frigiola $A$. Predictors for heparin resistance in patients undergoing coronary artery bypass grafting. Perfusion 1999; 14: 437-42.

16. Garvin S, Fitzgerald D, Muehlschlegel JD, et al. Heparin dose response is independent of preoperative antithrombin activity in patients undergoing coronary artery bypass graft surgery using low heparin concentrations. Anesth Analg 2010; 111: 856-61. 
17. Tollefsen DM, Majerus DW, Blank MK. Heparin cofactor II. Purification and properties of a heparin-dependent inhibitor of thrombin in human plasma. J Biol Chem 1982; 257: 2162-9.

18. Weitz JI, Leslie B, Hudoba M. Thrombin binds to soluble fibrin degradation products where it is protected from inhibition by heparin-antithrombin but susceptible to inactivation by antithrombin-independent inhibitors. Circulation 1998; 97: 54452.

19. Barzu T, van Rijn JL, Petitou M, Tobelem G, Caen JP. Heparin degradation in the endothelial cells. Thromb Res 1987; 47: 601-9.

20. Young E, Prins M, Levine MN, Hirsh J. Heparin binding to plasma proteins, an important mechanism for heparin resistance. Thromb Haemost 1992; 67: 639-43.

21. Levy JH, Cormack JG, Morales A. Heparin neutralization by recombinant platelet factor 4 and protamine. Anesth Analg 1995; 81: 35-7.

22. Wu HF, Lundblad RL, Church FC. Neutralization of heparin activity by neutrophil lactoferrin. Blood 1995; 85: 421-8.

23. Yee DL, O'Brien SH, Young G. Pharmacokinetics and pharmacodynamics of anticoagulants in paediatric patients. Clin Pharmacokinet 2013; 52: 967-80.
24. Newall F, Johnston L, Ignjatovic V, Monagle P. Unfractionated heparin therapy in infants and children. Pediatrics 2009; 123: e510-8.

25. Guzzetta NA, Amin SJ, Tosone AK, Miller BE. Change in heparin potency and effects on the activated clotting time in children undergoing cardiopulmonary bypass. Anesth Analg 2012; 115: 921-4.

26. Estes JW. Clinical pharmacokinetics of heparin. Clin Pharmacokinet 1980; 5: 204-20.

27. Despotis GJ, Summerfield AL, Joist JH, et al. Comparison of activated coagulation time and whole blood heparin measurements with laboratory plasma anti-Xa heparin concentration in patients having cardiac operations. J Thorac Cardiovasc Surg 1994; 108: 1076-82.

28. Guzzetta NA, Monitz HG, Fernandez JD, Fazlollah TM, Knezevic $A$, Miller BE. Correlations between activated clotting time values and heparin concentration measurements in young infants undergoing cardiopulmonary bypass. Anesth Analg 2010; 111: 173-9. 